\title{
COMPARAÇÃO DE MÉTODOS PARA A DETERMINAÇÃO DE AÇÚCARES REDUTORES E TOTAIS EM MEL ${ }^{1}$
}

\author{
Roberto do Nascimento SILVA², Valdirene Neves MONTEIRO², Joana D‘Arc Ximenes ALCANFOR, \\ Elaine Meire ASSIS ${ }^{4}$, Eduardo Ramirez ASQUIERI ${ }^{5, *}$
}

\section{RESUMO}

Este trabalho teve como objetivo comparar vários métodos para a determinação de açúcares redutores (A.R) e totais (A.T) em mel, a fim de suprir carências dos laboratórios de análises de alimentos das indústrias alimentícias e adaptar o método de ADNS (Ácido 3,5Dinitrossalicílico) para análise de açúcares totais. Foram utilizadas quinze amostras de méis procedentes de diferentes cidades do estado de Goiás. Foram utilizados os seguintes métodos: Antrona, ADNS, complexometria com EDTA (Ácido etilenodiaminotetracético), Cromatografia em Camada Delgada, Fenol Sulfúrico, Lane \& Eynon, Luff-Schoorl, Munson-Walker, Refratometria na escala Brix e SomogyiNelson. Para açúcares redutores os métodos Luff-School e Munson-Walker foram significativamente diferentes $(p \geq 0,05)$ dos demais, apresentando em geral, valores menores. Para os açúcares totais e sacarose todos os métodos foram significativamente iguais. Os méis não apresentam quantidades de sacarose acima do estabelecido pela legislação vigente do Ministério da Agricultura.

Palavras-chave: mel; açúcares redutores e totais; métodos.

\section{SUMMARY}

COMPARISION METHODS FOR THE DETERMINATION OF REDUCERS SUGARS AND TOTAL IN HONEY. This work had as objective compares several methods for the determination of reducers sugars (R.S) and total (T.S) in honey kindred of supplying to lacks of analyses laboratories' industry foods. Fifteen samples of honeys coming from different cities of the State of Goiás were used. The following methods were used: Antrona, ADNS (3,5-Dinitrissalicilic acid), EDTA (Etilenediaminetetracetic acid) complexometry, Thin Layer Cromatrography, Sulfuric Phenol, Lane \& Eynon, Luff-Schoorl, Munson-Walker, Brix refratometry and Somogyi-Nelson. For reducers sugars the methods Luff-School and Munson-Walker were significantly different $(p \geq 0,05)$ of the others, presenting in general, smaller values. For the total sugars and sucrose all the methods were significantly same. The honeys don't present amounts of sucrose above the established for the effective legislation of the Ministry of the Agriculture.

Keywords: honey; reducers sugars and total; methods.

\section{1 - INTRODUÇÃO}

Os monossacarídeos, glicose e frutose são açúcares redutores por possuírem grupo carbonílico e cetônico livres, capazes de se oxidarem na presença de agentes oxidantes em soluções alcalinas. Os dissacarideos que não possuem essa característica sem sofrerem hidrólise da ligação glicosídica são denominados de açúcares não redutores. A análise desses açúcares é uma atividade rotineira nos laboratórios das indústrias alimentícias, nas quais pode-se observar uma certa carência, no que se refere a técnicas padronizadas para análises.

Diversos reativos são utilizados para demonstrar a presença de grupos redutores, em açúcares [21]. De fato, os monossacarideos podem ser oxidados por agentes oxidantes relativamente suaves tais como os íons férricos $\left(\mathrm{Fe}^{3+}\right)$ e cúprico $\left(\mathrm{Cu}^{2+}\right)$.

Para se estimar o teor de açúcares redutores e açúcares redutores totais em alimentos, existem vários métodos químicos não seletivos que fornecem resultados, com elevado grau de confiabilidade, quando utilizados corretamente após eliminação de interferentes [1]. Ou-

\footnotetext{
Recebido para publicação em 28/05/2001. Aceito para publicação em 05/02/2003 (000662)

${ }^{2}$ ICB/UFG.

${ }^{3}$ IPTESP/UFG

${ }^{4}$ FANUT/UFG. assis@fanut.ufg.br

${ }^{5}$ FF/UFG. Universidade Federal de Goiás. Laboratório de Tecnologia e Bioquimica de Alimentos. asquieri@farmacia.ufg.br

* A quem a correspondência deve ser enviada.
}

tros métodos mais seletivos vêm sendo estudados e aplicados em menor escala como a cromatografia líquida de alta eficiência (CLAE), que identifica uma maior variedade de carboidratos na amostra, por ser mais sensivel, além de possuir um tempo de análise pequeno [4] e as determinações enzimáticas que sendo muito específicas, não vão sofrer ação de possiveis interferentes com grupos redutores livres [6, 17].

Os métodos químicos clássicos conhecidos para a análise de açúcares redutores são na sua maioria fundamentados na redução de íons cobre em soluções alcalinas (solução de Fehling), mas também existem aqueles fundamentados na desidratação dos açúcares, por uso de ácidos concentrados, com posterior coloração com compostos orgânicos, além da simples redução de compostos orgânicos, formando outros compostos de coloração mensurável na região do visivel [5, 9, 12, 13].

Os métodos podem ser agrupados tanto em titulométricos (EDTA e Lane-Enyon, Luff-Schoorl) [11], gravimétricos (Musson-Walker) [19] e espectrofotométricos (ADNS, Antrona, Fenol-Sulfúrico, Somogyi-Nelson) [12, 13, 21].

Este trabalho foi realizado com o propósito de suprir a necessidade dos laboratórios de análise de alimentos no que se refere a técnicas na determinação de açúcares redutores (A.R) e açúcares totais (A.T), utilizando as metodologias de ADNS, Antrona, EDTA, Lane-Eynon, Fenol Sulfúrico, Luff-School, Munson-Walker, Somogyi-Nelson, cromatografia em camada delgada e refratometria medida na escala Brix. O mel goiano foi utilizado como amostra, visto ser um alimento muito rico em açúcares [7]. 


\section{2 - MATERIAL E MÉTODOS}

\section{1 - Materiais}

Os méis analisados foram adquiridos no período de março a julho de 1999 em feiras livres e nos estabelecimentos comerciais de 15 diferentes cidades do estado de Goiás: Anápolis, Bom Jesus, Caldazinha, Cristalina, Goiânia, Inhumas, Iporá, Itumbiara, Jataí, Mineiros, Porangatú, Quirinópolis, Rio Verde, Santa Isabel e Uruaçú. Após a aquisição os méis foram estocados em local seco e a temperatura de $25-30^{\circ} \mathrm{C}$.

\section{2 - Métodos}

\subsection{1 - Método do ácido 3-5-dinitrossalicílico}

A química da reação do ADNS com açúcares redutores está elucidada em parte. O ADNS é reduzido para ácido 3-amino-5-nitrossalicílico, enquanto que, no caso mais simples o grupamento aldeído parece ser oxidado a ácido aldônico (Figura 1). Entretanto a equivalência entre o ácido aminonitrossalicílico produzido e a quantidade do açúcar não é exata e diferentes açúcares produzem diferente intensidade na cor desenvolvida. Isso sugere que a química da reação deva ser mais complexa que a apresenta$\mathrm{da}$, podendo estar relacionada com as reações de decomposição de açúcares em solução alcalina [12]. As análises foram feitas segundo MILLER [12]. Os açúcares redutores foram quantificados por espectrofotometria com comprimento de onda de $540 \mathrm{~nm}$, utilizando-se uma curva padrão de glicose cuja concentração varia no intervalo de

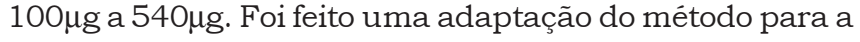
determinação do teor de açúcares totais. A hidrólise dos açúcares totais foi feito de acordo com MATISSEK, SCHENEPEL \& STEINER [11]. Adicionou-se à amostra $0,5 \mathrm{~mL}$ de $\mathrm{HCl}$ concentrado e incubou-se em banho-maria termostatizado a $60^{\circ} \mathrm{C}$ por 10 minutos. Após, neutralizou-se com $\mathrm{NaOH} 6 \mathrm{~N}$ e resfriou-se rapidamente em banho de gelo até a temperatura ambiente. O procedimento para a quantificação dos açúcares totais foi o mesmo utilizado para os açúcares redutores acima descritos.

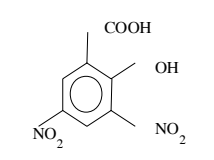

Ácido 3,5-dinitrossalicílico

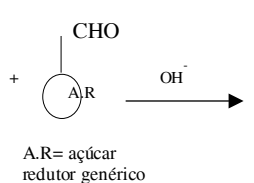

A.R= açúcar
redutor genérico

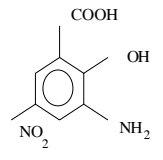
Ácido 3-amino-5-
nitrossalićlico

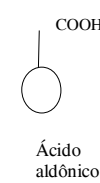

Ácido
aldônico
FIGURA 1. O ácido dinitrossalicílico é reduzido pelo açúcar redutor em meio alcalino a ácido 3-amino-5-nitrossalicílico formando ácido aldônico.

\subsection{2 - Método de antrona}

A reação de antrona se baseia na ação hidrolitica e desidratante do ácido sulfúrico concentrado sobre os carboidratos. Quando a reação é levada a efeito com carboidratos com ligações glicosídicas, estas são hidrolisadas e os açúcares simples desidratados para furfural ou hidroximetilfurfural. Essas substâncias se condensam com a antrona $(9,10$-dihidro-9-oxoantraceno) dando um produto de coloração azul petróleo [21]. As análises foram feitas de acordo com o método proposto por TREVELYAN, HARRISON [20]. Os açúcares totais foram quantificados por espectrofotometria a um comprimento de onda de $620 \mathrm{~nm}$, utilizando uma curva padrão de frutose $(100 \mu \mathrm{g} / \mathrm{mL})$ de intervalo 0-100 $\mu \mathrm{g}$.

\subsection{3 - Refratometria na escala Brix}

Constitui em um método físico para medir a quantidade de sólidos solúveis presentes em uma amostra. Baseia-se em um sistema de graduação de aparelhos especialmente para ser utilizado na indústria açucareira, mais precisamente na análise de açúcares em geral que estejam em solução. As análises foram feitas de acordo com SPENCER, MEAD [19]. As amostras preparadas a uma concentração final de $1 \%$ foram aplicadas diretamente no aparelho a uma temperatura de $25^{\circ} \mathrm{C}$ e feita as leituras.

\subsection{4 - Cromatografia em camada delgada}

A cromatografia em camada delgada (CCD) consiste na separação dos componentes de uma mistura através da migração diferencial sobre uma camada delgada de adsorvente retido sobre uma superficie plana [11]. Os açúcares foram identificados após a revelação com $200 \mathrm{~mL}$ de uma solução de ácido tricloroacético (10g), ácido ftálico $(5 \mathrm{~g})$ e paraminobenzóico $(1,2 \mathrm{~g})$ e uma solução de $15 \mathrm{~g}$ de uréia e $45 \mathrm{~mL}$ de ácido clorídrico ( $2 \mathrm{~mol} / \mathrm{L})$, utilizando-se padrões de glicose, frutose e sacarose a $1 \%$ de acordo com MATISSEK, SCHENEPEL \& STEINER [11].

\subsection{5 - Método fenol-sulfúrico}

Baseia-se na determinação de açúcares simples, polissacarídeos e seus derivados incluindo os metilésteres com grupos redutores livres, após a desidratação dos mesmos pelo ácido sulfúrico e subseqüente complexação dos produtos formados com o fenol. A mudança da cor da solução é medida na região do visivel e é proporcional à quantidade de açúcares presentes na amostra. A reação é sensivel e de cor estável [5]. As análises foram feitas de acordo com DUBOIS et al. [5]. Os teores de açúcares totais foram determinados por espectrofotometria a um comprimento de onda de 490nm utilizando-se uma curva padrão de glicose (1\%) de intervalo de10 a $90 \mu \mathrm{g}$.

\subsection{6 - Método complexométrico de EDTA}

Os açúcares presentes na amostra reagem com uma solução de cobre, antes e depois da inversão. Os íons $\mathrm{Cu}^{2+}$ se reduzem a Cu${ }^{+}$, que precipitará como $\mathrm{Cu}_{2} \mathrm{O} . \mathrm{O}$ excesso de cobre que não reagiu é determinado, posteriormente por complexometria com EDTA [11].

Para as análises das amostras primeiramente preparou-se uma solução alcalina de cobre (solução de Fehling) segundo a metodologia proposta por LANE, EYNON [9] e uma solução padrão de EDTA 0,01N, além 
de uma solução indicadora de murexida de acordo com MATISSEK, SCHENEPEL \& STEINER [11]. Para as determinações dos açúcares foi utilizado um fator de conversão que foi calculado titulando-se uma solução padrão de glicose a $0,1 \%$

\subsection{7 - Método Lane-Eynon}

No método o cobre do reativo de Fehling (solução alcalina de sulfato de cobre em tampão de tartarato duplo de sódio e potássio) é reduzido a óxido cuproso (Figura 2) [10]. As análises foram feitas segundo LANE, EYNON [9]. A solução de Fehling foi padronizada primeiramente utilizando-se uma solução de glicose a 1\%. A partir disso, calculou-se o fator de conversão para ser usado como parâmetro nas análises das amostras em questão.

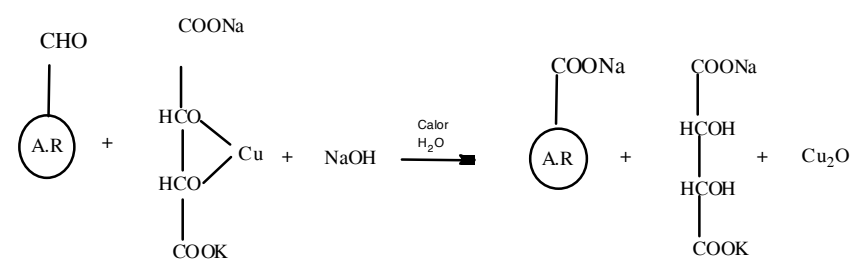

FIGURA 2. O sal de sódio que se forma com produto primário da oxidação do A.R sofre posterior oxidação, na seqüência da reação. $A \cdot R=$ açúcar redutor genérico

\subsection{8 - Método de Luff-Schoorl}

$\mathrm{O}$ açúcar redutor se oxidará e os îns $\mathrm{Cu}^{2+}$ se reduz a $\mathrm{Cu}^{+}$, que precipitará como $\mathrm{Cu}_{2} \mathrm{O}$. O excesso de íons $\mathrm{Cu}^{2+}$ se determina iodometricamente [21].

$2 \mathrm{Cu}^{2+}+$ Açúcar redutor $\rightarrow \mathrm{Cu}_{2} \mathrm{O}$

$2 \mathrm{Cu}^{2++} 4 \mathrm{I}^{-} \rightarrow 2 \mathrm{CuI}_{2} \rightarrow 2 \mathrm{CuI}+\mathrm{I}_{2}$

$\mathrm{I}_{2}+2 \mathrm{~S}_{2} \mathrm{O}_{3}{ }^{2-} \rightarrow 2 \mathrm{I}^{-}+\mathrm{S}_{4} \mathrm{O}_{6}{ }^{2-}$

As amostras foram analisadas de acordo com o método proposto por MATISSEK, SCHENEPEL \& STEINER [11]. A determinação de açúcares foi feita a partir de um fator de conversão titulando-se uma solução de tiossulfato de sódio $0,1 \mathrm{~mol} / \mathrm{L}$ com uma solução padrão de glicose $1 \%$.

\subsection{9 - Método Munson-Walker}

Fundamenta-se na quantificação do precipitado de óxido cuproso formado após a redução de íons cobre bivalentes, em meio básico, pelos açúcares redutores (glicose e frutose) [19]. As análises foram feitas de acordo com SPENCER, MEAD [19]. A determinação das porcentagens de açúcares foram feitas utilizando uma tabela de conversão fornecida pelos mesmos autores.

\subsubsection{0 - Método de Somogyi-Nelson}

Os glicídeos redutores aquecidos em meio alcalino, transformam-se em enodióis que reduzem o íon cúprico presente a cuproso. O óxido cuproso assim formado re- duz a reação arsênio-molibídico a óxido de molibdênio de coloração azul cuja intensidade de cor é proporcional a quantidade de açúcares redutores existentes na amostra $[13,18]$. As análises foram feitas segundo SOMOGYI [18] e NELSON [13]. O teor de açúcares redutores foi calculado por espectrofotometria a $510 \mathrm{~nm}$, utilizandose uma curva padrão construída a partir de uma solução de glicose $(100 \mathrm{mg} / \mathrm{mL})$ com intervalo de 0 a $180 \mu \mathrm{g}$.

\subsubsection{1 - Análises estatísticas}

As análises estatísticas foram realizadas de acordo com PIMENTEL [14]. Para os resultados, usou-se o delineamento inteiramente casualizado, onde foram feitas análises de variância, com posterior comparação das diferenças entre as médias pelo teste de Tukey ao nivel de $5 \%$ de probabilidade.

\section{3 - RESULTADOS E DISCUSSÃo}

A Figura 3 representa a cromatografia em camada delgada das amostras de mel. A glicose e a frutose possuem o mesmo peso molecular e nas condições de análise não foi possivel separá-las. A mancha mais abaixo representa a sacarose. O interessante, aqui a ressaltar, é que todas amostras analisadas, apresentaram quantidades, ainda que diferenciadas, de sacarose, fato esse evidenciado nos ensaios químicos.

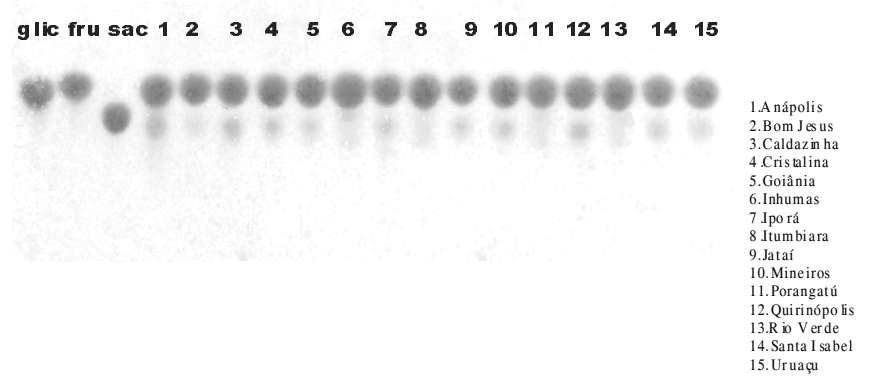

FIGURA 3. Cromatograma das amostras de mel. Padrões de glicose (glic), frutose (fru) e sacarose (sac) a $1,5 \%$ e amostras a $1 \%$.

A Tabela 1 mostra o resultado da refratometria medida em ${ }^{\circ}$ Brix. As amostras de méis são estatisticamente semelhantes no que se refere as quantidades de sólidos solúveis. No mel esta quantidade pode ser reproduzida com bastante exatidão para os açúcares totais, visto que a composição do mel em sólidos é basicamente de carboidratos.

TABELA 1. ${ }^{\circ}$ BRIX das amostras de mel

\begin{tabular}{lccccccccccccccc}
\hline \multicolumn{110}{c}{ AMOSTRAS* } \\
\hline \hline & 1 & 2 & 3 & 4 & 5 & 6 & 7 & 8 & 9 & 10 & 11 & 12 & 13 & 14 & 15 \\
\hline BRIX & 81,0 & 80,0 & 81,1 & 80,0 & 79,1 & 79,9 & 78,3 & 84,0 & 81,3 & 81,3 & 85,0 & 82,2 & 83,0 & 80,0 & 79,5 \\
BRumeradas de acordo com a Figura 1.
\end{tabular}

A Tabela 2 mostra os resultados obtidos em porcentagens dos açúcares redutores nos méis do estado de Goiás, na sua maioria acima de $70 \%$, com exceção da 
amostra número 3. Os métodos apresentaram diferenças significativas a $0,05 \mathrm{p}=2,16$. O teste de Tukey foi realizado a fim de se estabelecer qual o melhor método. O valor de t encontrado a 0,05 com um grau de liberdade do resíduo de 89 foi de 4,35. Após as análises verificou-se que apenas os métodos de Luff-School e de Munson-Walker, diferem dos demais.

As metodologias que se fundamentam na espectrofotometria, se comportaram melhor na determinação de açúcares redutores frente as que se fundamentam tanto na titulometria quanto na gravimetria.

TABELA 2. Percentagem (\%) de açúcares redutores obtida por diferentes métodos*

\begin{tabular}{|c|c|c|c|c|c|c|c|c|c|c|c|c|c|c|c|}
\hline MÉTODOS & 1 & 2 & 3 & 4 & 5 & 6 & 7 & 8 & 9 & 10 & 11 & 12 & 13 & 14 & 15 \\
\hline ADNS & 78,69 & 75,90 & 77,17 & 77,10 & 80,10 & 78,34 & 73,52 & 77,57 & $\overline{78,72}$ & 79,53 & 80,26 & 80,25 & 79,73 & 79,21 & 79,42 \\
\hline EDTA & 76,99 & 76,56 & 67,19 & 77,35 & 79,11 & $77,16^{-}$ & 74,84 & 75,51 & 74,66 & 77,61 & 76,84 & 76,92 & 74,45 & 78,30 & 78,40 \\
\hline Lane-Eynon & 79,53 & 77,80 & 67,44 & 77,32 & 75,44 & 78,65 & 73,84 & 78,31 & 82,60 & 80,50 & 83,69 & 80,28 & 82,93 & 85,47 & 80,30 \\
\hline Luff-Schoorl & 71,92 & 67,80 & 68,80 & 70,80 & 72,96 & 74,52 & 71,92 & 74,00 & 77,80 & 77,12 & 76,60 & 80,24 & 68,88 & 78,68 & 76,08 \\
\hline M.Walker & 69,90 & 68,50 & 70,15 & 71,75 & 71,75 & 72,30 & 71,30 & 72,00 & 70,90 & 72,00 & 80,80 & 70,60 & 69,00 & 70,60 & 73,15 \\
\hline S. Nelson & 77,54 & 77,50 & 68,31 & 72,90 & 77,50 & 76,57 & 69,30 & 71,89 & 78,42 & 70,32 & 77,48 & 79,34 & 79,34 & 80,01 & 74,53 \\
\hline
\end{tabular}

Os resultados das análises de açúcares totais, mostrados na Tabela 3 não apresentaram diferenças significativas, em nivel de 0,05.

Os métodos tradicionalmente usados nas pesquisas de açúcares totais se fundamentam principalmente na hidrólise ou digestão dos compostos orgânicos pelo tratamento com ácidos, geralmente o ácido sulfúrico, produzindo cores devido à reação. É o caso dos métodos de antrona e de Fenol sulfúrico, muito utilizados nas indústrias de alimentos. Estes dois métodos apresentam algumas desvantagens em relação aos demais, como trabalhar com grandes quantidades de ácido sulfúrico [20].

Alguns trabalhos que comparam diferentes métodos de determinação de açúcares em xarope, geléia, suco, cana-de-açúcar e melaço vem sendo conduzidos por vários autores $[1,3,8,15,16]$ que obtiveram para a metodologia de Lane, Eynon, valores superestimados para sacarose e concluem que esta metodologia inclui muitos não açúcares que após a hidrólise ácida tornam-se redutores do licor de Fehling.

Um dos objetivos deste trabalho foi a adaptação da metodologia de ADNS para a determinação de açúcares totais, visto que este método é usado apenas na determinação de açúcares redutores. Tal objetivo foi alcançado, na medida em que os resultados obtidos, frente aos outros métodos, não apresentaram diferenças significativas, como discutido acima.

Referente a quantidade de sacarose nos méis analisados, estes não ultrapassaram a quantidade de $8 \%$ permitida de acordo com a legislação brasileira do Ministério da Agricultura [2]. As eficiências dos métodos na determinação de sacarose também foram avaliadas, pois de acordo com os dados da Tabela 4, os métodos não apresentaram diferença significativa em nivel 0,05.
TABELA 3. Percentagem (\%) de açúcares totais obtida por diferentes métodos*.

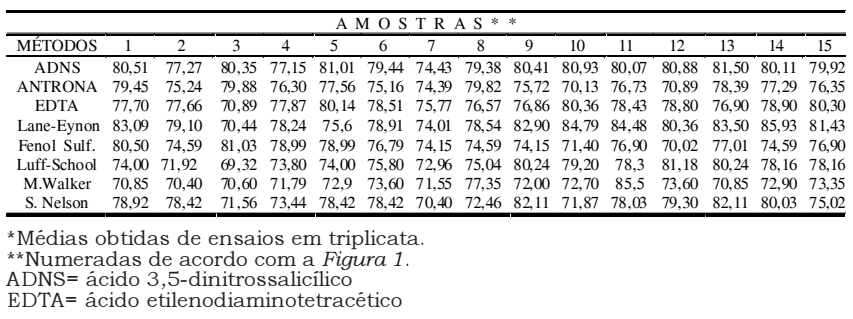

TABELA 4. Percentagem (\%) de sacarose em amostras de mel obtida por diferentes métodos*.

\begin{tabular}{|c|c|c|c|c|c|c|c|c|c|c|c|c|c|c|c|}
\hline MÉTODOS & 1 & 2 & 3 & 4 & 5 & 6 & 7 & 8 & 9 & 10 & 11 & 12 & 13 & 14 & 15 \\
\hline ADNS & 1,82 & 1,37 & 3,18 & 0,04 & 0,91 & 1,10 & 0,91 & 1,81 & 1,69 & 1,40 & 0,43 & 0,62 & 1,82 & 0,90 & $\overline{0,50}$ \\
\hline EDTA & 0,71 & 1,10 & 3,70 & 0,523 & 1,03 & 1,35 & 0,93 & 1,06 & 2,2 & 2,75 & 1,59 & 1,88 & 2,49 & 0,57 & 1,63 \\
\hline Lane-Eynon & 3,56 & 1,30 & 3,00 & 0,92 & 0,16 & 0,26 & 0,17 & 0,23 & 0,3 & 4,29 & 0,79 & 0,07 & 0,57 & 0,46 & 1,13 \\
\hline Luff-Schoorl & 2,08 & 4,12 & 0,52 & 3,00 & 1,04 & 1,28 & 1,04 & 1,04 & 2,44 & 2,08 & 1,70 & 1,56 & 1,92 & 1,56 & 2,08 \\
\hline M.Walker & 0,95 & 1,90 & 0,45 & 0,04 & 1,15 & 1,30 & 0,25 & 5,35 & 1,10 & 0,70 & 4,70 & 3,00 & 1,85 & 2,30 & 0,20 \\
\hline S. Nelson & 1,38 & 0,92 & 3,25 & 0,54 & 0,92 & 1,85 & 1,10 & 0,57 & 3,69 & 1,49 & 0,55 & 0,04 & 2,77 & 0,27 & 0,49 \\
\hline
\end{tabular}

A escolha de um método para a determinação de sacarose em alimentos, a ser implementado em um laboratório de análise de química de alimentos deve levar em conta a viabilidade técnica, o comportamento químico do método frente a interferentes e a amostra a ser analisada [11].

$\mathrm{Um}$ aspecto importante a ser ressaltado na determinação de açúcares totais em alimentos é a neutralização das amostras após a hidrólise ácida, pois o meio reacional não deve estar ácido, ou seja, em pH abaixo de 4, uma vez que propicia a formação de substâncias químicas denominadas de hidroximetilfurfural [1] que serão quantificadas como açúcares totais ou que interferem na quantificação por qualquer método, seja espectrofotométrico, gravimétrico ou titulométrico.

\section{4 - CONCLUSÕES}

- Dentre os métodos analisados apenas Luff-School e Musson-Walker se diferiram estatisticamente dos demais na quantificação de açúcares redutores.

- Referente a quantificação de açúcares totais, nenhum método diferiu estatisticamente, dos demais. A adaptação da metodologia de ADNS para tal quantificação foi realizada com sucesso. A padronização da hidrólise ácida para a determinação de açúcares totais, deve ser feita levando-se em conta, as concentrações de sacarose presente em cada tipo de alimento.

- Em todas as amostras de mel analisadas a quantidade de sacarose está dentro dos valores que a legislação do Ministério da Agricultura Brasileiro (Portaria no 001 de 24 de março de 1980) estabelece, sendo permitido no máximo $8 \%$.

\section{5 -REFERÊNCIAS BIBLIOGRÁFICAS}

[1] BORGES, M.T.M.R.; PARAZZI, C.; PIEDADE, S.M.D.S. Avaliação de Métodos Químicos de Determinação de 
Açúcares Redutores em Xaropes. Anais do $4^{\circ}$. Congresso Nacional da STAB. VIII Convenção da ACTALAC, Olinda, Pe, Brasil, 8-13 novembro de 1987 .

[2] BRASIL, Ministério da Agricultura. Secretaria de Inspenção Animal. Portaria n. 001 de 24 de março de 1980. Diário Oficial, 28 março de 1980.

[3] BREVIL, C.; SADDLER, J.N. Comparison of the 3,5dinitrosalicylic acid and Nelson-Somogyi methods of assaying for reducing sugars and determining cellulase activity. Enzyne and Microb. Technol., v. 7, n. 7, p. 327-332, 1985.

[4] CANO, C.B.; ALMEIDA-MURADIAN, L.B. Análise de padrões de carboidratos normalmente encontrados no mel por cromatografia líquida de alta eficiência (CLAE)- Parte I. XVI Congresso Brasileiro de Ciências e Tecnologia de Alimentos, “Alimento, População e Desenvolvimento", Rio de Janeiro, Brasil, 15-17 de julho de 1998.

[5] DUBOIS, M.; GILles, K. A.; HAMILTON, J. K.; REBERS, P. A.; SMITH, F. Colorimetric Method form Determination of Sugars and Related Substaces. Nature, v. 28, n. 3, p. 350 - 356, 1956.

[6] FROST, G.M. Industrial enzyme applications industrial. Biotechnology Wales, v. 3, n. 11, p. 1-11, 1984.

[7] GRANE, E. 1985 - Livro do Mel, 2ed., São Paulo p. 226.

[8] HART, F.; GIRARD, C.L.; SOARES, J.M. Comparação entre técnicas na determinação de açúcares totais, redutores e não redutores em geléias. XVI Congresso Brasileiro de Ciências e Tecnologia de Alimentos, "Alimento, População e Desenvolvimento", Rio de Janeiro, Brasil, 15-17 de julho de 1998

[9] LANE, J. H.; EYNON, L. Determination of reducing sugars by Fehling's solution with methylene blue indicator, Normam Rodge, London, 8p., 1934.

[10] LEHNIGER, L.A; NELSON,L.D.; COX, M.M. Princípios de Bioquímica, $2^{\circ}$ ed., p. 227 - 228, 1995.
[11] MATISSEK, R.; SCHENEPEL, F.M.; STEINER, G. Analisis de los Alimentos: Fundamentos, metodos, aplicaciones. Editorial Acribia, S.A- España, 1998.

[12] MILLER, G. L. Use of dinitrosalicylic acid reagent for determination of reducing sugar. Analytical Chemistry, v. 31, n. 3, p. $426-428,1959$.

[13] NELSON, N. A fotometric adaptaion of Somogyi method for the determination of glucose. J.Biol.Chen. , v. 153, p. 375-80, 1944.

[14] PIMENTEL GOMES, F. Curso de estatística experimental. 10.ed. São Paulo: Nobel, 430p. , 1982.

[15] SCHAFFLER, K.J. Preminary comparison of polarimetric and gas chromatography methods of the estimation of sucurose in sugar cane juice and molasses. Ann. Congr. South african sugar technologists' association, 52 Mount Edgecombe. Proceedings. p. 220 - 223, 1976.

[16] SCHAFFLER, K.J.; SMITH, I.A. True sucurose versus pol; the effect on cane quality and factory balance data. Ann. Congr. South african sugar technologists' association, 52 mount edgecombe. Proceedings. p. 59 - 63, 1978.

[17] SHORE, M.; SARGENT, D. Modern instrumental techniques of analysis and the sugar industry. Int. Sugar Journal, v. 83, n. 991, p. 199 - 205, 1981.

[18] SOMOGY, M. A New Reagent for Determination of Sugars. A new Sugar Reagent, May p. 61-68, 1945.

[19] SPENCER, G.L.; MEADE, G.P. Special Reagentes. Cane Sugar Handbook, New York, Wiley, 1945.

[20] TREVELYAN, W.E.; HARRISON, T.S. Dosagem de glicídeos totais pelo método de antrona. J.Biochem., v. 50, p. 292, 1952 .

[21] VILLELA, G.G., BACILA, M.; TASTALDI, H. Técnicas e Experimentos de Bioquímica, ed. Guanabara, p. 552. São Paulo, SP, 1973.

[22] WHITE JUNIOR, J.W. The hive and the honey bee, Dandant \& Sons. Inc. Hamilton, Illinois. p. 491-530, 1975. 